\title{
Big Data in Marketing Arena. Big Opportunity, Big Challenge, and Research Trends: An Integrated View
}

\author{
Mohammad Saleem ALSHURA ${ }^{1}$ \\ Abdelrahim $Z A B A D I^{2}$ \\ Mohammad ABUGHAZALEH ${ }^{3}$
}

\begin{abstract}
Big Data has earned much attention from the IT industry and academia. Given the research interest on Big Data in the marketing field, thus, authors intend to present an integrated view based on the previous literature with the aim of identifying the major trends in this field. Particularly, the analysis focus on pertinent terms and topics related to three "B's": Big Data, Big Opportunities/benefits, Big challenges. A systematic integrated literature review was carried out through a strict search approach that identified. A total of 650 articles published between 2010 and 2018 indexed in EBSCO database were collected and scrutinized. The results of the previous studies on big data and marketing revealed that they were limited to discuss the technical and research fields and did not clearly consistent with sophisticated technologies towards the benefits of marketing, and it has not yet reached the level of marketers' ambition. Over and above, findings show that research in big data applications and practices to marketing is still in early stages, thus, making it necessary to promote more direct efforts towards the business for big data to thrive in the marketing domain. This paper is specifically relevant to marketing firms and departments concerned in the evolution of marketing activities and abilities to increase customer basis. Furthermore, it is also useful to compare several international studies trend as this study takes a perspective globally. The study provides priceless information and an in-depth integrated view of big data relevant to opportunities and challenges that marketing encountered. Furthermore, it opens new insights into the topic area by emphasizing for further future studies and research directions.
\end{abstract}

KEYWORDS: Big data, big Opportunities, big challenges, marketing, systematic literature review.

JEL CLASSIFICATION: $M 1, M 2, M 3$

\section{INTRODUCTION}

Data collection to enhance competitiveness is not a new phenomenon; it has been over the last decades (Purcell, B, 2013; Biesdorf et al., 2013). Nowadays, massive amounts of data are gathered and stored by firms, with the hopeful of being beneficial in the future. "Data is the oil of the economies" as (Wedel \& Kannan, 2016) indicated. Generation of massive amounts

\footnotetext{
${ }^{1}$ Management Department, College of Business \& Finance, The World Islamic Science \& Education University (Wise), Jordan, mhmadshura@yahoo.com

2 IT department, College of Engineering, University of Business\&Technology (UBT), Saudi Arabia, azabadi_2011@hotmail.com

${ }^{3}$ IT Interface department, Khalifa Industrial Zone Abu Dhabi, Kizad, United Arab Emirates, mohammed.abughazaleh@gmail.com
} 
of data every minute has transformed work methods in business organizations and different industry sectors alike.

Big Data is ever more seen as a fundamental element of a well-functioning business. A number of academic reports and published articles have indicated to the growing utilize of big data across different economic sectors (Taylor \& Schroeder, 2014; Thomas \& McSharry, 2015; Manyika et al., 2011) and its prospect to promote productivity, competence, and growth. The understanding that use of data has become increasingly significant and widespread has led to discussions of how better to promote big data approaches through regulation and managing, and means of policy (Pasquale, 2015). Any such policies must be based on an understanding of the prevailing landscape of how big data is being used by organizations, and how various data sources are being used.

In many business fields and industries, the big data has revolutionized marketing arena as a result of advances in Big Data algorithms and advanced analytics techniques, big data is revolutionizing how firms attract greater customer responsiveness and gain greater customer insights (Chen et al., 2012). Despite the huge data, the term is a bit redundant, but maximizing the use of this technology remains a challenge for many marketers today. According to Ovum estimates, the huge data market is expected to grow from $\$ 1.7$ billion in 2016 to $\$ 9.4$ billion by 2020 .

Companies will begin to consider increasing the interest of increasingly big data (Rakity, 2017). Managing such loads of data and extracting a proper knowledge from it for supporting decisions poses a big opportunity and big challenge at the same time. This led to the emerging of the term "Big Data"(BD). It is a data set that is so big and complex that is difficult to process with just one database management system tool or traditional data processing applications (McKinsey Global Institute, 2011). Big Data nowadays is globally spread and vastly accepted, also representing an alternate of a vanguard in terms of information management, despite this does not come without controversy (Fan \& Bifet, 2013). Indeed, as (Chen et al., 2012) revealed, that practitioners need to move quickly forward "from big data to Big Impact" for effectively availing from the many features that offered by big data (Chen et al., 2012).

Big Data is often described by three (at times four or even five) V's: Volume, Velocity, and Variety (Marr, 2016; Wedel \& Kannan, 2016; Beyer, 2011). From a storage and computational point of view, the "volume" and "velocity" are important, while the "variety" is important from an analytics point of view (Wedel \& Kannan, 2016). Marr believes that the hype about "big data" is a whirlwind in a cup, and just a name may disappear, but a revolution and the phenomenon will remain and collect momentum only, also, he anticipates that data will merely become the "new normal" in a coming few years' time when all firms utilize data to improve what to do, and how (Marr, 2016). In general, we don't agree with this point of view.

The effective use of Big Data has transformed economies and launches a new phase of productivity and growth according to McKinsey (Kaisler et al., 2013; Manyika et al., 2011). The primary competitive strategy of current business organizations relies on capitalizing the valuable knowledge beyond big data. New competitors must be able to attract employees who possess high skills in treating Big Data. By harnessing Big Data, businesses gain many benefits, such as new products and services, improved customer service, acquire new customers, open new markets, increase operational efficiency, and inform strategic direction (Khan et al., 2014). 
The support of decision making is crucial issue for marketers, by providing insights to help in answering the following vital questions like; (Amado et al., 2018), what is the most appropriate product and service for a particular market; how to advertise in that market; through what channels will communicate; at what points in suitable time and for what price; and supported by what kind of promotional and advertising activities. Big Data can impact on marketers in many different methods; it benefits them by making it easy for them to get a better idea regarding the changing customers' tastes and preferences. Big Data also makes it easy to develop the appropriate advertising strategies to the firm's target customer base.

However, understanding and dealing with this growing volume and variety of data are still an issue in which to look. While big data is on the top of many marketing firms agenda's, few of them are getting value out of it. With Big Data, users not only face numerous attractive opportunities but also encounter challenges (Ahrens et al., 2011). Therefore; this study seeks to furnish an integrated view for better understanding for three issues relevant to big data in the marketing arena. These issues include: 1. what is the big data; what are the marketers' viewpoint (how do they define this concept and how is it's being beneficial in their industry). 2. What are the big opportunities that big data offered? 3. The study explores also the big challenges marketers encountered, and what is the right steps that can be taken to confront and reduce these challenges; and 4. Research trends issues, conclusion, and future directions are also presented in this paper.

In addressing these issues, a systematic integrated literature review was carried out through a strict search approach that identified a total of 650 articles/reports published from 2010 to 2018 were scrutinized. The rest of the paper is organized as follows: Section 2 discusses the research methodology; Section 3 presents the theoretical lens; Sections 4 and 5 shows the opportunities and challenges of big data in marketing arena respectively; Section 6 concludes the paper and recommendations for future studies.

\section{METHODOLOGY}

A systematic review approach was adopted in order to synthesize existing literature and identify the most relevant researchers in a comprehensive manner. We have adopted strategy that intends to completeness our research in the Big Data domain by looking to its benefits, opportunities, and challenges in the marketing area. Such systematic literature reviews are will support in avoiding that the results of the literature are biased. To identify the most associated publications to this research study, we have highlighted on finding the relevant journal articles about marketing and big data during a specific time covering the last 8 years. The study was conducted by selecting the journal articles including reviews or under printing in the period specified from 2010 to 2018.

The reason for selection this framework is due to the increase of web interest in Big Data over the past few years (Amado et al., 2018; Ozkose et al., 2015). High-level concepts were included in this query in the domain of Big Data and marketing. The scope of picked sciences from EBSCO databases are management, business, accounting; computer science; and economics. The total number of gathered articles was 650, from a total of 56 different journals, this is conclusive evidence that a variety of journals are interested in Big Data and marketing. 


\section{THEORETICAL LENS}

As the study title indicates, the data is big, also the opportunities and benefits, but marketers need to acknowledge the accompanying challenges that come with using leveraging this big data. Big data opportunities and challenges have been investigated in several previous studies, but few studies have been conducted in the marketing arena. This study presents: (a) a comprehensive survey of Big Data definitions and characteristics; (b) a discussion of the linkage of big data and marketing; (c) review the opportunities and challenges associated with big data in marketing; (d) Research trends issues, conclusion, and future directions are presented in this paper.

\subsection{Big Data: What is it?}

More data was generated in the last few years than in the whole former history of humanity. At the same time, Data is flowing at a higher speed in real-time. Over and above, data, for the time being, is much more varied which including not only numeric data but also for example but also not limited to images, text or video data for example but also not limited to. It's a term on everyone's tongues, and the hot topic for researchers, but do you really know what we're talking and writing about?

Traditional database systems are inefficient when storing, processing, and analyzing the rapidly growing amount of data or big data (Manyika et al., 2011). The term "Big Data" has been used in the previous literature but is relatively new in business and IT (Hashem, 2015). To locate an accurate and homogeneous definition of this controversial term is not possible in practice because it is not formal or agreed upon by researchers and scientists, we would like to define and explain the term big data which are closely connected to our topic and mentioned in this research study. However, for the better understanding of this term, we will present some familiar definitions.

The classical and widespread definition created by McKinsey Global Institute (McKinsey Global Institute, 2011): "Big Data refers to datasets whose size is beyond the capacity of typical database software tools to capture, store, manage, and analyze data" (McKinsey Global Institute, 2011). This definition points to the great challenge faced by business organizations because of their large data. Moreover, the kind and amount of this data are so massive and diverse that the dealing with it in traditional ways and tools the companies were utilizing is unattainable. In his article, John Gantz has described Big Data as following: "Big Data technologies describe a new generation of technologies and architectures, designed to extract an economic worth from very large volumes of a wide variety of data, by enabling high-velocity capture, discovery and/or analysis" (Reinsel \& Gantz, 2011).

As a global term for huge and complicated series of technologies, this definition more describes the big data which are purposed to manage and analyze mainly unstructured data which are significant for the working and evolution of a firm. However, this definition doesn't describe one important aspect of big data concept as defined by (Laney \& Beyer, 2012) "Big data are high volume, high velocity, and/or high variety information assets that demand new forms of processing to discover insight, enable enhanced decision making, and optimization of processes “. This definition uses the 3V's (volume, variety, velocity) model proposed by (Beyer, 2011). The model highlights an e-commerce trend in data management that faces challenges to manage volume or size of data, variety or different sources of data and velocity or speed of data creation. Some studies declare volume as the main characteristic of big data without providing a pure definition (Borkar et al., 2012). 
According to SAS Institute Inc., "Big Data refers to the ever-increasing volume, velocity, variety, variability, and complexity of information" (SAS Institute Inc, 2015). However, other researchers introduced additional characteristics for big data, such as veracity, value, variability, and complexity (Gani, 2016; Paul, 2013). The 3V's model, or its derivations, is the most common descriptions of the term "big data.' From the point of view of marketing firms, Dig Data can be described as the inevitable result of the new marketing landscapes that resulted from the global digital revolution we are now experiencing.

Numerous companies today find themselves captive to internal data, paralytic by internal silos, and implements traditional methods of marketing. Consequently, consumers are losing their patience, and shareholders are demanding growth and excellence, while marketers are struggling to encounter these massive challenges. Big Data provides a strategic roadmap for executives who wish to remove the mess and begin moving towards building a sustainable competitive advantage. Big Data helps marketing institutions to explore the treatment offered by data-driven marketing. Also, big data reveals patterns of marketing for customers' behavior and assured methods to promote customer practices. In the following, these issues are described in detail.

\subsection{Big data and Marketing: A Brief Overview:}

Nowadays, Big Data is anywhere, whether in the shape of structured data, such as organizations traditional databases (e.g., customer relationship management (CRM) or unstructured data, driven by new information and communication technologies and user editing platforms (e.g., text, images, and videos) (Lansley \& Longley, 2016). Digital technological advance has led to a significant effect on marketing theories and practices alike. Technology has given innovative opportunities to capture quality customer's better data and increase focus on the relationship with them, in addition to the growing of their insight, and Customer Relationship Management (CRM).

Moreover, the Internet has promoted consumers' interact with brands, as well as the radical transformation in the marketing economics in addition to create numerous new marketing strategies instead of traditional methods which are from the perspective of marketers no longer worthwhile. As a result of those rapid changes and the huge amount of data accumulated, businesses in general and marketing, in particular, are obliged to turn their working methods, and data-driven decision making is becoming more and more a portion of an organization' essence and its policy.

The emergence of Big Data recently prompted traditional marketing tools to work in more powerful, innovative and productive methods (Grishikashvili et al., 2014). Marketing is defined by the American Marketing Association as: "Marketing is the activity, set of firms, and operations to creating, communicating, delivering, and exchanging offerings that have value for customers, consumer, stakeholders, and society as a whole" (American Marketing Association (AMA), 2013). According to this definition, the relationship between Big Data and marketing is obvious.

In business nowadays, big data is the big thing and the blood for any business. It shifted our lives and revolutionizes the way of doing business. Marketing domain is not an exception of course, as marketing departments all over the world are struggling to implement big data into their practices. All over the world, big data has generated priceless opportunities for marketing firms'. The easy access to massive amounts of information based on customer interactions has enabled marketers to know more about the customer's attitudes and needs 
(Sluis, 2014). According to Bessen (1993), through using the two-way information flow between the marketer and the customer the value of big data for marketing departments' can best be explained (Bessen, 1993).

To get insight from more data faster and cheaper, formally, big data understood as technologies and techniques. From the marketers' point of view, Big Data can be seen as the ability to work with further agility; designing data-driven programs that adapt to customers interact with products, service, and brands (Forrester, 2014). For this, marketers must embed the agility from Big Data practices across the firm on four specific levels: innovation in processes; investment in novel technologies and resources; wide-based measurement to customer experiences; and strategy pursued by the executive management (Forrester, 2014). The new Big Data technologies are ideally positioned to meet the challenges marketers encounter towards seizing more opportunities and achieving big benefits in the revenues and performance of the organization in general.

We would like to point out here, that having Big Data and its accumulation in an organizations does not necessarily lead to better marketing. It can be seen as a buried treasure, a raw material, and a basic element, it is not the data itself this is very important. To some extent, it's the insights that derived from it; the decisions we make and the actions we take that make everything is different. The following section presents some of opportunities/benefits which marketers acquire when they use Big Data through reviewing many of the previous literature.

\section{BIG DATA: BIG OPPORTUNITIES}

Among all the Big data application, the operational and genuine Big Data's benefits for marketers are many, these benefits can be seen as big opportunities; creating a more accurate profile for targeted customers and consumers; predicting customer response to marketing messages and product/service offerings and Personalizing those messages; optimizing production / service and distribution strategy; creating and use more accurate assessment measures; perfecting digital marketing and campaign-based strategies; retaining more customers less expensively; Obtaining product/service insights, among other tactics. This is not meant to be an exhaustive list, but the marriage of Big Data and marketing certainly does enhance long-held marketing capabilities and give rise to an impressive set of new ones.

Furthermore, in marketing, big data supplying insights into which content is the most effective at every phase of marketing strategies; enhanced investments in systems of Customer Relationship Management (CRM); in addition to increasing transformation rates strategies; potential engagement; conversion rates; revenue; and customer's lifetime value . In many business fields and industries, Big Data has revolutionized marketing as a result of progress in its algorithms and the developed analytics techniques. Big data is revolutionizing how marketing firms attract more customer interactions and gain greater customer insights.

However, possessing the Big Data does not necessarily leads to bigger marketing, but the potentials are available, Big Data can be seen as; raw materials, secret treasure, and vital assets of the firm. We would like to emphasize here again that the existence of data is not important itself, rather it's valuable ideas derived from it, and the decisions are taken that creates all difference. By merging an integrated marketing management strategy with Big Data, a considerable effect in the following three key domains by marketers will take place. 
Big data has enabled marketers to move from knowing customer demographically to understand them as an individual; the amount of information that is incredible about the consumer makes it possible for marketers to tailor their products and services, offers, and activities to meet the expectations of a particular customer and his preferences (BrandBa.Se, 2015). Marketing with the use of big data will compel marketers to gain certain skills in order to make use of such data, and they will chase insights by combining a mix of findings and data. Big data has started to provide marketers with a real-time and holistic view of the consumers and their ongoing activities.

All in all, marketers have been armed with advertising optimization capabilities based on the increasing amount of big data available to them or data they can obtain (Fulgoni, 2013). At the moment of interaction, marketers urgently need to improve the customer experience. Now, most marketing efforts actually moving towards generating this interaction-based capability, from analyzing and understanding customer interactions to secure technology infrastructures, adequate budget, and staff to managing customer interactions across channels and different programs (Amado et al., 2018).

\section{BIG DATA CHALLENGES IN MARKETING}

Big Data changed business strategy, but marketers find it difficult to handle the data. Use Big Data still a big challenge for marketers. In spite of several benefits obtained from big data, but marketers also need to acknowledge the accompanying challenges that come with using leveraging this data. Due to the Internet, social media, and big data, at the present time, it is easier than ever to establish two-way information flow. Accordingly, another challenge for many marketers has moved from having too little information to having too much information arrive from too many sources. The massive amount of information has marketers into what has become known as insight fishermen or snipers chances. According to Krajicek (2013) creating an information ecosystem by compiling data patterns from several sources is one of the paramount challenges for marketing departments.

Krajicek (2013) blamed many marketing departments for committing that the "more is better", he argues that they seem to believe that adding more information sources will result in a better outcome. Marketers commit a lot of time "in the cloud" looking at macro trends is also a common error (Krajicek, 2013). The existence of terabytes of data, but no one to successfully interpret it, is a great error, as well as the fact that many marketers lack skills that would enable them to use big data successfully (Vriens \& Brazell, 2013; Ross et al., 2013).

A lot of data and big insights are wasted when big data is not being invested by small data and interpreted based on the integrations and relationships that it's based on (Ross et al., 2013; Fox \& Do, 2013). Big data requires being operated at so as to generate the prospective competitive advantages. Another challenge for big data is the overlap / and or the clash between marketing and sales departments, big data can erode the obligations of long-term marketing with a view to promoting short-term sales (Fox \& Do, 2013).

Reliance on big data in companies tends to cultivate mental decision-making in the short term according to (Fulgoni, 2013) warning. The implications on individual's privacy are one of the fundamental criticisms for utilizing of big data in marketing (i.e. much information about consumers that can be stored in firms will be exposed to intervention in their own lives. So, there have been voices calling for moral guidelines for the commercial utilization of big data, moreover, some have gone to call for self-imposed regulation in order to maintain the consumers' trust (Sluis, 2014; Nunan \& Di Dominico, 2013; Cumbley, 2013). 
Using big data is not the only prerequisite for success. Only skillful marketers with wide knowledge in psychology and sociology can implement it in the way that will enable them to create attractive marketing campaigns and outflank their competition. Almost in all big firms, harnessing the potential benefits of big data on the agenda of chief marketing officers is not surprising. What are the best methods to reap benefits? What are the big opportunities and big challenges? Particularly, monetizing the big data is what they want to know. In this study, from the authors' point of view, an opportunity is a benefit, and the challenge is an opportunity, many successful companies have transformed the challenge into opportunity and benefit. Marketers can meet the twin challenges of improving performance and customer experience by improving big data maturity (Forrester, 2014). Marketing success always depends on a two-way information flow between marketers and customers, thus, the challenge that faces the marketers lies in collecting detailed demographic and customers' lifestyle information that can be utilized as a basis for effective marketing activities (Bessen, 1993).

\section{CONCLUSIONS AND RECOMMENDATIONS FOR FUTURE RESEARCH}

The motivation for the current study is motivated by the need for a better understanding of the impact of big data on marketing through discusses the potential opportunities/benefits and the challenges and research trends in this area from different perspectives. A total of 650 articles published between 2010 and 2018 indexed in EBSCO database were collected and scrutinized. This large number of articles makes the use of systematic review of literature an appropriate option for a better evaluation. The study reached several key conclusions; the results revealed that big data in marketing has seen an increasing attention over the few last years, with every year doubling the previous one in publication output figures.

This result coincided with many previous studies (Amado et al., 2018; Grishikashvili et al., 2014). However, few works were found in addressing the benefits that marketers could potentially attain out of Big Data solutions in particular. According to (Akter \& Wamba, 2016), next to the determining the border for a Big Data solutions, it is vitally important that the implementation should be aligned with the challenges posed by the specificities of the business.

The results also disclosed a research gap in multidisciplinary research, for instance, technology researchers need to better align the benefits of Big Data and its challenges toward marketing. It is worth noting in this regard that we note that although many marketing terms (e.g., customer retention and loyalty, customer segmentation, and customer engagement) are often seen as being associated with data analysis, few appear highlighted in the addressed topics. The ones that addressed in the literature revealed a weak relationship in the topic when talking about the significance of Big Data in marketing (Amado et al., 2018).

Further, we discussed numerous academic point of view, we concluded that there was a gap between academia and practices. In sum, results indicate that many business and different industries are starting to narrow this gaps and challenges and put innovative mechanisms in place to make an effective harness of big data in marketing. As any research study, some limitations should be acknowledged which could also be addressed in future studies. First, studies on big data in the marketing arena are as yet in its early stages as data volume continues accumulating. Therefore, further studies are required to address this hot topic in the research area. Second, as big data hides several challenges represented in its three characteristics 3 V's: Volume, Velocity, and Variety, future research could address the fundamental requirements in designing marketing solutions to meet up with these challenges. Third, the study did not address the challenges that come with using the big data technology and its implications on consumers' privacy issues, future studies can address these vital subjects in marketing. 


\section{REFERENCES}

Ahrens, J., Hendrickson, B., Long, G., Miller, S., Ross, R., \& Williams, D. (2011). Dataintensive science in the US DOE: case studies and future challenges. Computing in Science and Engineering, 13(6), 14-23. https://doi.org/10.1109/MCSE.2011.77

Akter, S., \& Wamba, S.F. (2016). Big data analytics in E-commerce: A systematic review and agenda for future research. Electronic Markets, 26 (2), 173-194. https://doi.org/10.1007/s12525-016-0219-0

Amado, A., Cortez, P., Rita, P., \& Morobe, S. (2018). Research trends on Big Data in Marketing: A text mining and topic modeling based literature analysis. European Research on Management and Business, 24(1), 1-7. https://doi.org/10.1016/ j.iedeen.2017.06.002

American Marketing Association (AMA). (2013). Retrieved August 23, 2017, from:

https://www.ama.org/AboutAMA/Pages/Definition-of-Marketing.aspx.

Beyer, M. (2011). Gartner says solving 'Big Data' challenge involves more than just managing volumes of data. https://www.gartner.com/newsroom/id/1731916

Bessen, J. (1993). Riding the marketing information wave, Harvard Business Review, 71 (5), 150-160.

Borkar, V., Carey, M. J., \& Li, C. (2012). Inside Big Data management: Ogres, onions, or parfaits? in Proc. 15th Int. Conf. Extending Database Technol., 3-14. https://doi.org/10.1145/2247596.2247598

BrandBa.Se. (2015). Big data: Opportunities and challenges for marketers. Retrieved January 29, 2015, from: www.brandba.se/blog/2014/8/19/big-data-opportunities-and-challengesfor-marketers.

Chen, H., Chiang, R.H., \& Storey, V.C. (2012). Business intelligence and analytics: From big data to a big impact. MIS Quarterly, 36(4), 1165-1188.

Cumbley, R., \& Church, P. (2013). Is "Big Data" creepy? Computer Law \& Security Review 29(5), 601-609. https://doi.org/10.1016/j.clsr.2013.07.007.

Fan, W., \& Bifet, A. (2013). Mining big data: Current status, and forecast to the future. ACM SIGKDD Explorations Newsletter, 14(2), 1-5. https://doi.org/10.1145/2481244. 2481246.

Forrester Consulting Thought Leadership Paper Commissioned By Strong View. (2014). Marketing's Big Leap Forward Overcome the Urgent Challenge to Improve Customer Experience and Marketing Performance. Retrieved July 10, 2015, from

https://app.compendium.com/uploads/user/4f91a3ee.../1394484576218.pdf

Fox, S., \& Do, T. (2013). Getting real about Big Data: applying critical realism to analyze Big Data hype. International Journal of Managing Projects in Business, 6(4), 739-760.

Fulgoni, G. (2013). Big Data: Friend or Foe of Digital Advertising? Five Ways Marketers Should Use Digital Big Data to Their Advantage. Journal of Advertising Research, 53(4), 372-376.

Gani, A. (2016). A survey on indexing techniques for big data: Taxonomy and performance evaluation, Knowledge and Information Systems, 46(2), 241-284. https://doi.org/ 10.1007/s10115-015-0830-y.

Grishikashvili, K. et al. (2014). An investigation into Big Data Impact on Digital Marketing. International Conference on Communication, Media, Technology and Design 24-26 April 2014. Istanbul - Turkey.

Hashem, I.A.T. (2015). The rise of "big data' on cloud computing: Review and open research issues. Information Systems, 47, 89 - 115. https://doi.org/10.1016/j.is.2014.07.006.

Kaisler, S., Armour, F., Espinosa, J.A., \& Money, W. (2013). Big data: issues and challenges moving forward. Proceedings of the IEEE 46th Annual Hawaii International Conference 
on System Sciences (HICSS '13); January 2013; pp. 995-1004. https://doi.org/10.1109/HICSS.2013.645

Khan, N. et al. (2014). Big Data: Survey, Technologies, Opportunities, and Challenges. Scientific World Journal.2014: 712826. Published online 2014 Jul 17. https://doi.org $/ 10.1155 / 2014 / 712826$

Krajicek, D. (2013). Market research and the ethics of big data. Marketing Insight, 25(1), 8-9

Laney, D., \& Beyer, M. (2012). The Importance of Big Data: A Definition. Retrieved April 01, 2015, from:https://www.gartner.com/doc/2057415.

Lansley, G., \& Longley, P. (2016). Deriving age and gender from forenames for consumer analytics. Journal of Retailing and Consumer Services, 30, 271-278. https://doi.org/10.1016/j.jretconser.2016.02.007

Manyika, J., Chui, M., \& Brown, B. (2011). Big data: the next frontier for innovation, competition, and productivity. Washington, DC : McKinsey Global Institute.

Marr, B. (2016). Big data in practice:Big Data in Practice: How 45 Successful Companies Used Big Data Analytics to Deliver Extraordinary Results. Chichester : Wiley.

McKinsey Global Institute. (2011). Big Data: The next frontier for innovation, competition, and productivity. Retrieved May 25, 2017, from: https://www.mckinsey.com /.../McKinsey/.../McKinsey\%20Digital/.../Big\%20data\%20T

Nunan, D., \& Di Dominico, M. (2013). Market research and the ethics of big data. International Journal of Market Research, 55(4), 2-13.

Ozkose, H. et al. (2015). Yesterday, today and tomorrow of big data. Procedia - Social and Behavioral Sciences, 195, 1042-1050. https://doi.org/10.1016/j.sbspro.2015.06.147

Pasquale, F. (2015). The black box society. Cambridge : MA: Harvard University Press., https://doi.org/10.4159/harvard.9780674736061.

Paul, A. (2013). Video search and indexing with reinforcement agent for interactive multimedia services, ACM Transactions on Embedded Computing Systems, 12(2), 1-16. https://doi.org/10.1145/2423636.2423643.

Purcell, B. (2013). The emergence of" big data" technology and analytics. Journal of Technology Research 4, 1-7.

Rakity, A. (2017). Content Marketing. Ovum Recognized for Excellence in Sales Lead Responsiveness by Outsel. London : Ovum TMT intellegence.

Reinsel, D., \& Gantz, J. (2011). Extracting value from chaos. Retrieved April 02, 2015 from: http://www.emc.com/collateral/analyst-reports/idc- extracting-value-from-chaos-ar.pdf.

Ross, J. W., Beath, C.M., \& Quaadgras, A. (2013). You May Not Need Big Data After All, Harvard Business Review, 91(12), 90-98.

SAS Institute Inc. (n.d.) THE POWER TO KNOW. Retrieved January 30, 2018, from: https://www.sas.com/en_us/insights/big-data/big-data-marketing.html.

Sluis, S. (2014). DMA13 Marketers Must Carefully Consider Big Data Strategies, CRM Magazine, 18(1), 8.

Taylor, L. \& Schroeder, R. (2014). Is bigger better? The emergence of big data as a tool for international development policy. GeoJournal, 80, 503-518. https://doi.org/ 10.1007/s10708-014-9603-5

Thomas, R., \& McSharry, P. (2015). Big data revolution What farmers, doctors and insurance agents teach us about discovering big data patterns? Chichester: Wiley.

Vriens, M., \& Brazell, J. (2013). The COMPETITIVE Advantage. Marketing Insight, 25(3), $32-38$.

Wedel, M., \& Kannan, P.K. (2016). Marketing analytics for data-rich environments. Journal of Marketing, 80, 97-121. https://doi.org/10.1509/jm.15.0413 